\title{
On two kinds of fulminating gold
}

\section{Dumas}

To cite this article: M. Dumas (1831) On two kinds of fulminating gold, Philosophical Magazine Series 2, 9:49, 69-70, DOI: 10.1080/14786443108647537

To link to this article: http://dx.doi.org/10.1080/14786443108647537

册 Published online: 01 Jun 2009.

6 Submit your article to this journal $\pi$

LII Article views: 2

Q View related articles $₫$ 
oxalate of potash and ammonia; sulphuric acid converts it into sulphate of ammonia, carbonic acid and carbonic oxide: and these changes appear to be effected by the addition of the vapour of water in the proportions above stated.

Many animal substances, such as albumen, gelatin, fibrin, \&c., act with potash precisely like oxamide, and the uric and hippuric acids much resemble it in this respect. M. Dumas is occupied in further researches on this subject.-Ann. de Chimie, June 1830.

ON TWO KINDS OF FUIMINATING GOLD. BY M. DUMAS.

Basil Valentine long since described the remarkable properties of fulminating gold. Three suppositions have been offered respecting its nature : first, that it is an ammoniuret, or a compound of ammonia and oxide of gold; secondly, it has been considered as an azoturet, just as a chloride is produced by the mutual action of oxide of gold and muriatic acid; and thirdly, it has been considered as analogous to salts, the azoturet of gold acting as an acid and ammonia as the base.

One hundred parts of fulminating gold treated with oxide of copper and also with oxide of lead, in the well-known manner, gave from 9.7 to 9.9 of azote and 13 of water ; the quantity of chlorine was determined by that of the chloride of silver yielded by the muriate of copper left after analysis ; 100 of fulminating gold gave 4.5 of chlorine. The quantity of gold was found by mixing the fulminating gold with ten times its weight of sulphur and gently heating the mixture. When the sulphur is heated to about $302^{\circ} \mathrm{Fahr}$. the mass swells, gases are disengaged, and the vapour of sulphur burns. When all the sulphur is expelled, the residue is heated to redness, and pure gold remains, amounting to about 73 or 74 per cent. The necessary corrections being made, fulminating gold appears to consist of

These are equivatent to

$$
\begin{array}{lr}
\text { Gold .... } & 73.0 \\
\text { Azote ... } & 5.0 \\
\text { Ammonia . . } & 6.0 \\
\text { Chlorine . . } & 4.5 \\
\text { Water . . } & 11.5 \\
\hline & 100.0
\end{array}
$$

$$
\begin{aligned}
& \text { Six atoms of gold ..... = =7458 or } 73.6--73.00 \\
& \text { Twelve atoms of azote . . . . = }=1062 \quad 10.4-9.88 \\
& \text { 'Two atoms of chlorine . . . = }=442 \quad 4.3-4.50 \\
& \text { Forty-two atoms of hydrogen }=263 \quad 2 \cdot 6-2 \cdot 20 \\
& \text { Nine atoms of oxygen } \ldots \ldots=900 \quad 9 \cdot 1--10 \cdot 42 \\
& \overline{10125} \quad \overrightarrow{100 \cdot 0} \quad \overline{\mathrm{J00} \cdot 00}
\end{aligned}
$$

It results from the preceding researches that common fulminating gold is a compound of two atoms of ammoniacal azoturet of gold and one atom of ammoniacal subchloride of gold, with a sufficient quan- 
tity of water to convert the azote into ammonia and the gold into oxide.

Scheele and Bergman have shown that oxide of gold when treated with ammonia is converted into a fulminating compound; this compound is undoubtedly different from the foregoing. To ascertain its nature, some oxide of gold was prepared by decomposing a boiling solution of muriate of gold with barytes, which precipitated aurate of barytes, the base of which was removed by dilute nitric acid. The remaining oxide of gold, which was well washed and pure, was put into strong solution of ammonia for twenty-four hours. The powder was washed by decantation, collected on a filter, and dried at $212^{\circ}$.

This powder is of a deep gray or olive colour ; it detonates strongly, but its appearance shows that it is different from common fulminating gold. When treated in the manner already described, it yielded

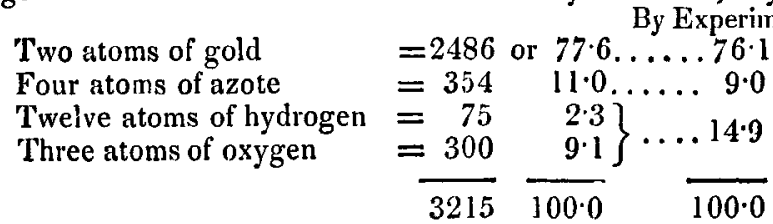

In this analysis the azote is not in sufficient quantity, but there is too much for an azoturet, and consequently greatly too much for an ammoniuret. It is probable that during desiccation the ammoniacal azoturet might lose a little ammonia. As, however, Bergman found that 100 of oxide of gold gave 120 of fulminating gold, and as according to the above analysis they should yield 118, it cannot be considered as far from correct. - Ibid.

\section{ON THE STATE OF MERCURY IN MERCURIAL OINTMENT.}

BY M. MITSCHERLICH.

The mercurial ointment employed occupied four weeks in preparing ; part of it was set to dissolve at a moderate temperature in alcohol containing caustic potash in solution. The mercury was separated in the metallic state and formed one globule at the bottom of the vessel ; the solution was filtered, and the metal was carefully removed from beneath the filter; a white matter remained, which was not removed by washing, and which heated in a tube gave no metallic mercury, nor did it sublime.

From this experiment it appears that the ointment does not contain oxide but metallic mercury. To be certain whether by the reaction of the alcohol and potash the oxide had not been reduced, the following experiment was made : $1 \cdot 101$ gramme of protoxide of mercury was triturated for a long time with lard. The ointment thus prepared was subjected to alcohol mixed with potash as in the preceding experiment. The portion remaining undissolved had not the least appearance of metallic mercury; it weighed 1.196: submitted to distillation with muriatic acid, no metallic mercuryappeared, but 1.29 gramme of protochloride of mercury, equivalent to 1.089 of protoxide of mercury. A small portion of the sediment when heated did not sublime.-Hensman's Repertoire, August 1830. 